\title{
Modulation of the Expression of Bloom Helicase by Estrogenic Agents
}

\author{
Takako Iso, ${ }^{a, b}$ Kazunobu FutAmi, ${ }^{a}$ Teruaki Iwamoto, ${ }^{b, c}$ and Yasuhiro Furuichi ${ }^{*}, a, b$ \\ ${ }^{a}$ GeneCare Research Institute Co., Ltd.; Kamakura, Kanagawa 247-0063, Japan: ${ }^{b}$ Core Research for Evolution Science \\ and Technology, Japan Science and Technology Agency; Kawaguchi, Saitama 332-0012, Japan: and ${ }^{c}$ Department of \\ Urology, St. Marianna University School of Medicine; Kawasaki, Kanagawa 216-8511, Japan. \\ Received September 19, 2006; accepted November 22, 2006
}

\begin{abstract}
We report that the expression of Bloom helicase $(B L M)$ was up-regulated by $17 \beta$-estradiol (E2) in estrogen receptor (ER)-positive mammary tumor MCF-7 cells, but was hardly modulated in ER-negative mammary tumor MDA-MB-231 cells. ER antagonist ICI182780 blocked the E2 effect on BLM expression in MCF-7 cells. From these results we conclude that ER participates in up-regulation of $B L M$ expression in MCF-7 cells by means of E2. Similar results were obtained when MCF-7 cells were treated with bisphenol A (BPA), an endocrine-disrupting chemical having a weak estrogenic activity. The ER binding ability of BPA is estimated at 1/1000 of E2 ability, and in this study about 1000-times more BPA was needed for the same levels of estrogenic effect of E2. The expression of cell-cycle associated genes, cdc6, MCM5, MCM2, Myt1, PCNA and AuroraA were up-regulated by E2 and BPA treatment in MCF-7 cells accompanied by up-regulation of $B L M$. In this $B L M$ promoter study, Sp1 elements in the upper region of $B L M$ modulated transcription, but were not indispensable for E2 response. Our results suggested that up-regulation of $B L M$ expression by E2 and BPA is ER-dependent and may be responsible for repair of DNA damage caused by the genotoxicity of these estrogenic agents.
\end{abstract}

Key words estrogen; endocrine-disrupting chemical; Bloom helicase; cell cycle

Carcinogenesis by $17 \beta$-estradiol (E2) is believed to be associated with its genotoxicity and stimulating activity of cell proliferation. ${ }^{1,2)}$ Studies using laboratory animals ${ }^{3,4)}$ and cultured cells ${ }^{5-8)}$ showed that E2 induces tumors. E2 suppresses detoxifying enzymes, such as catalase and glutathione- $S$-transferase, leading to an increase in genotoxicity by E2. ${ }^{9)}$ We showed previously that E2 causes DNA damage in mammary tumor MCF-7 cells assessed by single cell gel electrophoresis, the so-called Comet assay, and that the estrogen receptor (ER) is responsible for DNA damage. ${ }^{10)} \mathrm{A}$ similar effect was also observed for bisphenol A (BPA), an endocrine-disrupting chemical, ${ }^{11)}$ widely used as material for polycarbonate plastic and epoxy resin. BPA has a weak estrogenic activity to stimulate cell proliferation of ER-positive mammary tumor cells, and so is attracting considerable attention. ${ }^{12,13)}$ We showed previously the genotoxic effect of BPA as assessed by Comet assay, ${ }^{10)}$ but the BPA effect was much less than the effect of E2.

DNA microarray technology identifies profiles of estrogen responsive genes. ${ }^{14,15)}$ Cell cycle-associated genes whose expression is up-regulated by E2, particularly those having a role in DNA synthesis ${ }^{14)}$ have been studied. E2 down regulates antiproliferative and proapototic genes, ${ }^{14)}$ resulting in cell proliferation and cell survival in mammary tumor cells. During active proliferation cells need genome-maintaining enzymes, such as RecQ helicases, ${ }^{16)}$ to keep DNA fidelity in replictation. In this study, we focused on the expression of Bloom helicase $(B L M)$, a RecQ helicase, in MCF-7 cells stimulated by E2 to study the possible roles of BLM in E2treated cells.

\section{MATERIALS AND METHODS}

Chemicals E2 and BPA were purchased from Wako Pure Chemicals Industries, Ltd. (Osaka). Estrogen receptor antagonist ICI182780 was obtained from TOCRIS (Ellisville, MO, U.S.A.).
Cells, Cell Culture and Chemical Treatment Mammary tumor cells MCF-7 cells and MDA-MB-231 cells were obtained from the American Type Cell Culture (Bethesda, MA, U.S.A.). The cells were maintained in Dulbecco's Modified Eagle's Medium (DMEM) supplemented with $10 \%$ fetal bovine serum (FBS) and $50 \mu \mathrm{g} / \mathrm{ml}$ gentamycin (both from Sigma-Aldrich, St. Louis, MO, U.S.A.) in a humidified atmosphere under $5 \% \mathrm{CO}_{2}$ at $37^{\circ} \mathrm{C}$. For all chemical treatments, the cells were transferred to phenol red-free DMEM supplemented with $10 \%$ charcoal-dextran-stripped FBS (Hyclone, Logan, UT, U.S.A.) for $48 \mathrm{~h}$ before use to eliminate steroid hormones, including estrogen. The cells were treated with E2 or BPA for $48 \mathrm{~h}$ at indicated concentrations in figures. In time-course study, cells were treated with $10^{-10} \mathrm{M}$ E2 or $10^{-5} \mathrm{M}$ BPA. In additional experiments, pre-treatment with ICI182780 was done for $1 \mathrm{~h}$ and then by E2 or BPA treatments. The chemical agents were solubilized in ethanol and the final concentration of ethanol in the culture was adjusted to $0.1 \%$. Control culture cells were exposed to a culture medium containing $0.1 \%$ ethanol.

Gene Expression Reverse transcriptase-polymerase chain reaction (RT-PCR) based on the TaqMan method with ABI prism 7000 (Applied Biosystems, Foster City, CA, U.S.A.) was used to quantify BLM mRNA. A One-Step RTPCR Master Mix Reagents Kit and TaqMan MGB probes specific for $B L M$ was purchased from Applied Biosystems. Total RNA was extracted by using an RNeasy Mini kit (Qiagen, Valencia, CA, U.S.A.) according to the manufacturer's protocol. All RNA samples were assayed in triplicate. The number of changes in expression was calculated by using a comparative $\mathrm{C}_{\mathrm{T}}$ method (ABI PRISM user bulletin \#2) with human $\beta$-glucronidase expression as an internal control.

Antibodies and Immunoblotting Immunoblot analysis of BLM was done as described previously. ${ }^{17)}$ Briefly, after treatment with E2 or BPA, cells were solubilized in RIPA buffer containing $20 \mathrm{~mm}$ Tris- $\mathrm{HCl}(\mathrm{pH} 7.4), 0.1 \%$ sodium dodecyl sulfate (SDS), 1\% TritonX-100, 1\% sodium deoxy- 
cholate. The amounts of protein were determined by using the Bradford protein assay kit (BioRad, Hercules, CA, U.S.A.). Solubilized proteins $(50 \mu \mathrm{g})$ were electrophoresed on $2-15 \%$ SDS-polyacrylamide gels (Daiichi Pure Chemicals, Tokyo) at $200 \mathrm{~V}$ for $1 \mathrm{~h}$, and were electrophoretically transferred to a polyvinylidene fluoride membrane (Millipore, Billerica, MA, U.S.A.) for $90 \mathrm{~min}$ at $6 \mathrm{~V}$. Goat polyclonal antibodies against human BLM (C-18) was applied (Santa Cruz, CA, U.S.A.), and then by rabbit anti-goat immunoglobulin conjugated with horseradish peroxidase (DAKO, Glostrup, Denmark). The membrane was developed by using increased chemiluminescence using ECL Plus Western Blotting Detection Reagents (Amersham Life Science, Buckinghamshire, U.K.). Anti $\alpha$-actin (ICN, Costa Mesa, CA, U.S.A.) was used to normalize the sample loading.

Cap Site Cloning The transcription start sites of $B L M$ mRNA were determined by using an oligonucleotide-capping method $^{18)}$ according to the manufacturer's instructions. The cap site of the $B L M$ gene was amplified by PCR using $5^{\prime}$-replaced testis cDNA library supplied in Cap Site cDNA kit (NIPPONGENE, Tokyo). Briefly, primary PCR products were generated by the $5^{\prime}$ anchor primer supplied in the kit and human $B L M$ specific $3^{\prime}$ primer, 5'-TCTCTGTGTTTCCTGTCCTGCTGG-3', and then underwent nested PCR using the $5^{\prime}$ anchor primer supplied in the kit and human $B L M$ specific 3' nested primer 5'-TGTTGGGTAGAGGTTCACTGAAGG-3'. The second PCR products were cloned into pCR2.1 (Invitrogen, Carlsbad, CA, U.S.A.).

Plasmid Construction The upstream $2341 \mathrm{bp}$ fragment of $B L M$ containing putative promoter region of $B L M$ was amplified by using PCR and was inserted into the $B g l$ II site of pGL3-Basic vector (Promega, Madison, WI, U.S.A.) upstream of the firefly luciferase gene, which was used as a reporter gene (pGL3-BLM). A series of $5^{\prime}$ deletion mutants were generated from pGL3-BLM by digesting with $S a c$ I and Xho I, and then treated with exonucelase III and mung bean nuclease. $B L M$ promoter regions with various lengths were amplified by using PCR with specific primers and were inserted again into pGL-3 Basic plasmid. pGL3-rand was made by replacing the $B L M$ upstream region $(-258$ to +18$)$ with a random DNA sequence (103 bp) obtained from multi cloning sites of pBluescripts II KS+ (Sac I to Kpn I) (Stratagene, La Jolla, CA, U.S.A.). The directions and sizes of the modified gene inserts were confirmed by sequencing.

Transient Transfection Assay The $B L M$ promoter activity was assessed by firefly luciferase activity using Lumat LB9507 (Berthold, Bad Wildbad, Germany). Cells were subconfluently grown in phenol red-free DMEM supplemented with $10 \%$ charcoal-dextran-stripped FBS and were transfected with $B L M$ promoter-Luc plasmid DNA mixed with FuGENE (Roche Diagnostics, Indianapolis, IN, U.S.A.) (lipofectin method). After $4 \mathrm{~h}$ incubation, the medium was changed and the cells were stimulated with E2 or BPA for $48 \mathrm{~h}$. Other cells were treated with ICI182780 for $1 \mathrm{~h}$, and then by E2 or BPA treatments. Luciferase activity and protein concentrations in lysates were measured according to the manufacturer's instructions (Promega). Each treatment was done in quadruplicates and the data were shown as a mean with standard deviations.

Statistical Analysis Statistical analysis was done by using Dunnett's test.

\section{RESULTS}

Stimulation of BLM Expression by E2 in MCF-7 Cells E2-responsive MCF-7 cells were grown in a medium containing $10^{-12}-10^{-10} \mathrm{M}$ E2 for $48 \mathrm{~h}$. Figure 1A shows that $B L M$ mRNA levels increase markedly in a dose dependent manner. A time-course analysis indicated that $B L M$ mRNA
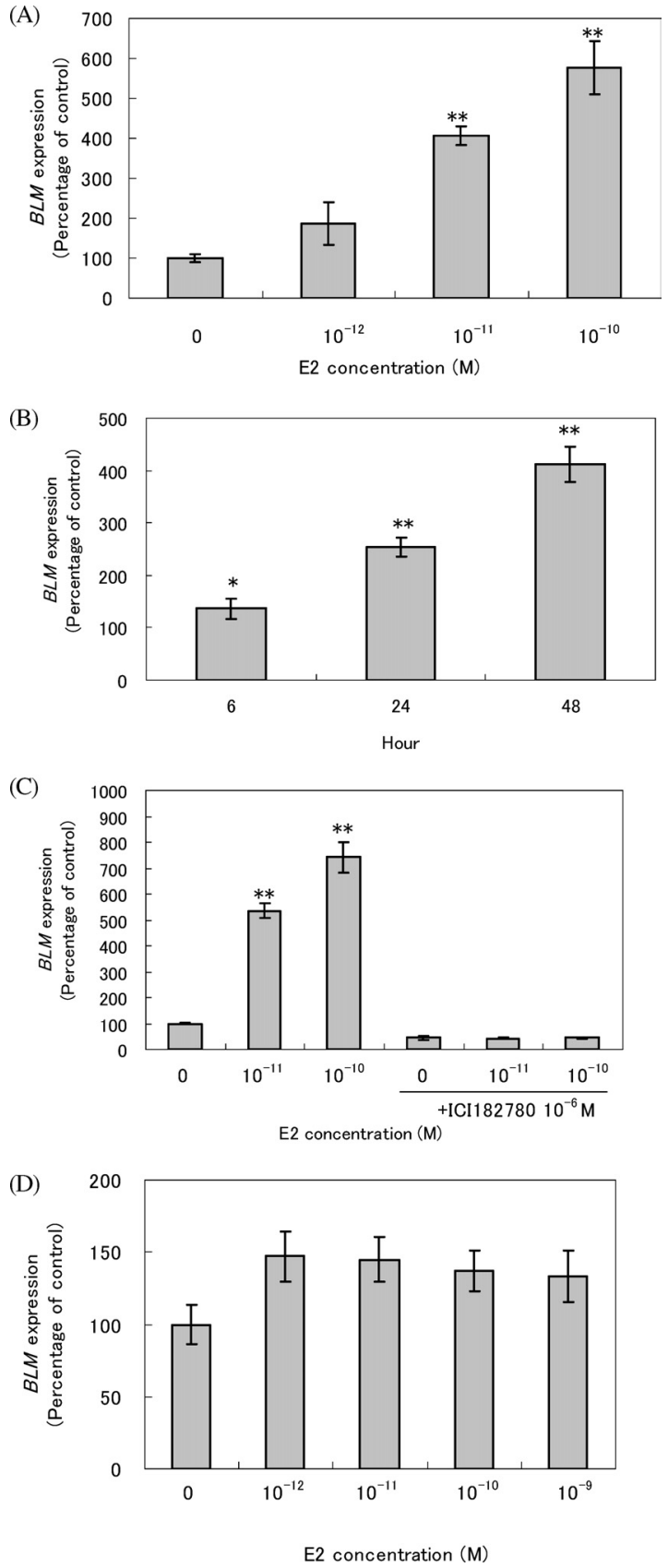

Fig. 1. BLM Expression after Treatment with E2

Each point represents mean \pm standard deviation of triplicate samples. The vertical axis indicates the percentage of expression of BLM (treated cells/untreated control cells). (A) Dose-dependent effect of E2 for $48 \mathrm{~h}$ in MCF-7 cells. (B) Time course of the effect of $10^{-10} \mathrm{M}$ E2 in MCF-7 cells. (C) Participation of the estrogen receptor in E2-induced $B L M$ expression. MCF-7 cells were treated with $10^{-6} \mathrm{M}$ ICI182780 (ICI) for $1 \mathrm{~h}$ and then by $10^{-11}$ and $10^{-10} \mathrm{M}$ E2. After $48 \mathrm{~h}$ the gene expression was assayed. Treatment with E2 alone on the left. (D) Expression of BLM in MDA-MB-231 cells at $48 \mathrm{~h}$ after treatment. ER-negative MDA-MB-231 cells were treated with E2 at the indicated concentrations. 
levels increased significantly even at $6 \mathrm{~h}$ after treatment with $10^{-10}{ }_{\mathrm{M}} \mathrm{E} 2$ (Fig. 1B). Because physiological concentrations of $\mathrm{E} 2$ in the blood are between $\mathrm{pg} / \mathrm{ml}$ and $\mathrm{ng} / \mathrm{ml}\left(10^{-10}\right.$, $\left.10^{-8} \mathrm{M}\right){ }^{19)}$ the effectve concentrations of Fig. $1 \mathrm{~A}\left(10^{-11}\right.$ or $10^{-10} \mathrm{M}$ ) are within or even less the physiological concentration. BLM mRNA was quantified for cells pre-treated with ER antagonist ICI182780 and then by E2. Pre-treatment with ICI182780 eliminated the increase in BLM mRNA expression by E2 to the control level (Fig. 1C) suggesting participation of ER in the stimulation of BLM mRNA. Basal levels of $B L M$ mRNA expression slightly decreased in the presence of ICI182780, but ICI182780 itself did not affect the cell number (data not shown). To study further the participation of ER in the up-regulation of $B L M$ expression, ER negative MDAMB-231 cells were treated with $10^{-12}-10^{-9} \mathrm{M}$ E2. BLM mRNA expression did not significantly increase in estrogen receptor-negative MDA-MB-231 cells at $48 \mathrm{~h}$ (Fig. 1D). These results support the idea that E2 up-regulates BLM expression by ER.

BPA has a weak estrogenic activity and binds to ER. ${ }^{11,20)}$ If ER participates in the regulation of $B L M$ expression, BPA is also expected to affect $B L M$ expression. Figure $2 \mathrm{~A}$ shows that $10^{-9}-10^{-5} \mathrm{M}$ BPA stimulates the expression of $B L M$ dose dependently. A time-course analysis showed that $10^{-5} \mathrm{M}$ BPA significantly stimulated $B L M$ mRNA expression at $24 \mathrm{~h}$
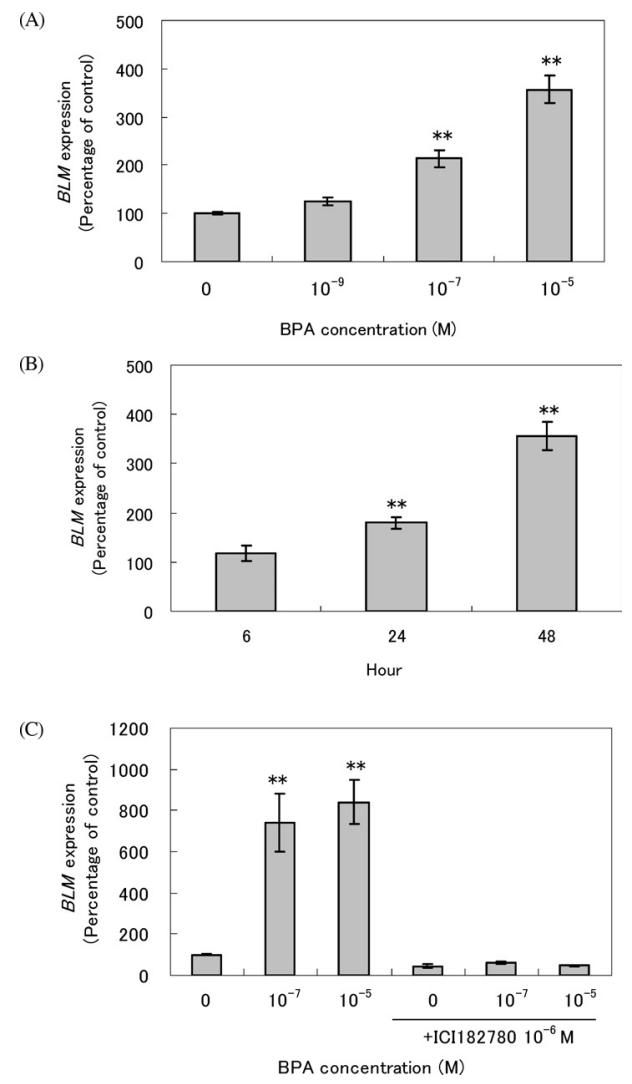

Fig. 2. BLM Expression Induced by BPA in MCF-7 Cells

Each point represents mean \pm standard deviation of triplicate samples. The vertical axis indicates the percentage of expression of BLM (treated cells/untreated control cells). (A) Dose response of BPA. MCF-7 cells were treated with BPA at the indicated concentrations for $48 \mathrm{~h}$. (B) Time course after treatment with $10^{-5} \mathrm{M}$ BPA. (C) Participation of the estrogen receptor in BPA-induced $B L M$ expression. MCF-7 cells were treated with $10^{-6} \mathrm{M}$ ICI182780 (ICI) for $1 \mathrm{~h}$ and then by $10^{-7}$ and $10^{-5} \mathrm{M}$ BPA. After $48 \mathrm{~h}$ the gene expression was assayed. Treatment with BPA alone is shown on the left. See also the legend of Fig. 1. after treatment (Fig. 2B). BPA also stimulates BLM expression, but needs a higher concentration to attain a similar level achieved by the effect of E2. Studies of ER affinity of BPA showed that its ER binding ability is about 1/1000 of E2 ability. ${ }^{20-22)}$ Thus, the difference in the effect on $B L M$ expression between E2 and BPA corresponds to the difference in their affinity with ER. BPA failed to increase $B L M$ mRNA expression in ER-negative MDA-MB-231 cells (data not shown). Figure $2 \mathrm{C}$ shows that ICI182780 inhibits the BPA effect on $B L M$ expression in MCF-7 cells similatr to the ICI182780 inhibition of the E2 effect on BLM expression. ICI182780 and BPA did not affect the cell number (data not shown). These results also support the idea that ER participates in the induction of BLM expression by BPA.

Response of Cell Cycle-Associated Genes E2 and BPA stimulate cell proliferation in MCF-7 cells ${ }^{11)}$ and E2 up-regulates the expression of cell cycle-associated genes in MCF-7 cells. $^{14,15)}$ Stimulation of the expression of most cell cycle-associated genes by E2 was obvious at $24 \mathrm{~h}$ or later after E2 treatment in this study. Figure 3 indicates that the expression of cell cycle-associated genes $c d c 6, M C M 5, M C M 2$, Myt1, PCNA and AuroraA is up-regulated at $24 \mathrm{~h}$ after treatment with E2 or BPA. These results are consistent with those of Frasor et al. ${ }^{14)}$ Generally, when E2 directly regulates genes, the expression of target genes is modulated within a couple of hours. ${ }^{14,15)}$ From this fact, together with our results for the time profile of gene expression, we assume that up-regulation of cell cycle-associated genes and $B L M$ genes may be a secondary response, not a primary response, by $\mathrm{E} 2$ stimulation.

Increase in BLM Protein Expression Figures 4A, B
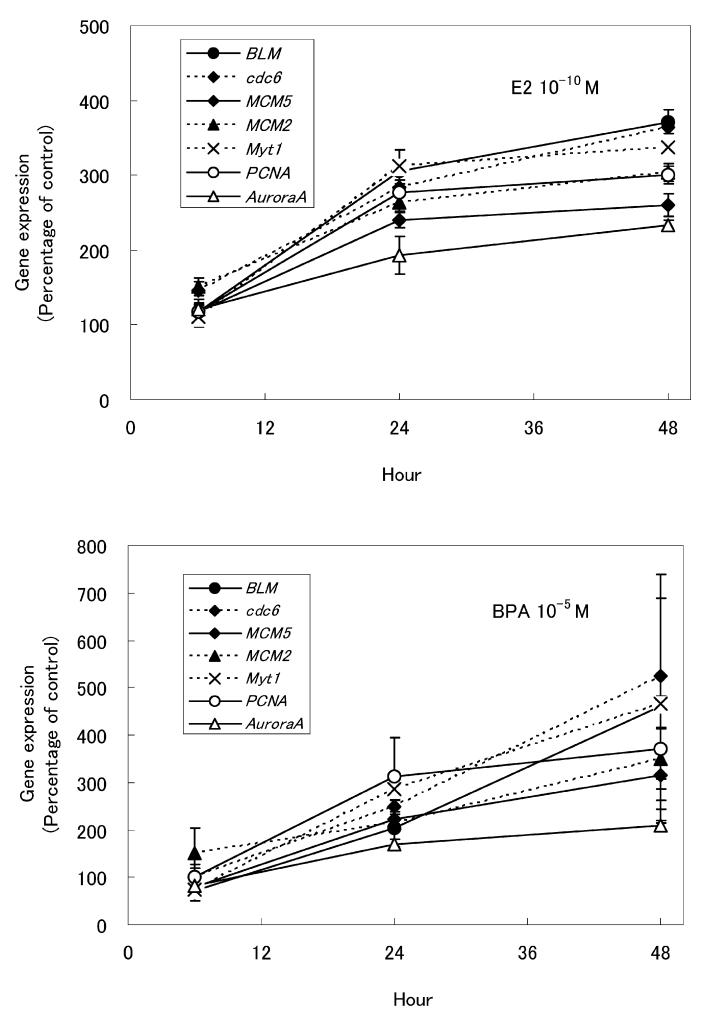

Fig. 3. Regulation of Cell Cycle-Associated Genes by E2 and BPA in MCF-7 Cells

MCF-7 cells were treated with $10^{-9} \mathrm{M} \mathrm{E} 2$ or $10^{-5} \mathrm{M}$ BPA. The expression levels of cell cycle-associated genes were determined at 6, 24 or $48 \mathrm{~h}$. See also the legend of Fig. 1 . 
(A) E2

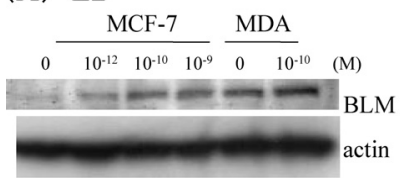

(B) BPA

MCF-7

$\begin{array}{llll}0 & 10^{-9} & 10^{-7} & 10^{-5}\end{array}$

$\because$ BLM

$=$ actin

Fig. 4. Expression of $B L M$ Protein in MCF-7 Cells and MDA-MB-231 Cells as Assessed by Immunoblotting

(A) MCF-7 cells and MDA-MB-231 cells were treated with E2 at the indicated concentrations for $72 \mathrm{~h}$. (B) MCF-7 cells were treated with BPA at the indicated concentrations for $72 \mathrm{~h}$. show by Western blotting the expression of BLM protein in MCF-7 cells by $72 \mathrm{~h}$-treatment with $10^{-12}-10^{-9} \mathrm{M}$ E2 or $10^{-9}-10^{-5} \mathrm{M}$ BPA. E2 or BPA stimulated the expression of BLM protein at higher doses. A similar result was also observed by a 48 h-treatment (data not shown). The BLM protein was not apparently up-regulated in the ER-negative MDA-MB-231 cells (Fig. 4A). The basal BLM protein level of MDA-MB-231 cells was higher than for MCF-7 cells.

Determination of Transcription Start Sites To study the regulation of $B L M$ expression by $\mathrm{E} 2$ treatment by identifying cis-regulatory elements in the $B L M$ promoter region,

(A)

\begin{tabular}{|c|c|c|c|}
\hline$\underset{-332}{\text { CCAAGAGAAT }}$ & GGGGTGCAGA CGCCTGGCTT & GGCC & -299 \\
\hline AACTGGCAAG & TCTCAGCTCT CAAACGCCCG & GGCTTTTCAA & -259 \\
\hline$\frac{\text { CCCGCCACAG }}{-257 \text { SP-1 }}$ & CCGGGTTCCA GCTGCCTACT & TCCTTTAAAG & -219 \\
\hline CCTTCACCGA & $\begin{array}{c}\text { CTCTAAAACA CCAAAAACAA } \\
-192\end{array}$ & $\frac{\mathrm{AGACCCAACT}}{-188}$ & -179 \\
\hline $\begin{array}{l}\text { AGCTCCGGAA } \\
-176\end{array}$ & GCCCGAGATG TAACCGTAGT & CATCTGACCC & -139 \\
\hline TCCCGTCCGG & ACTCTGATTG $\underset{-116}{\text { GGTTTGGAG }}$ & ATACGCGTCC & -99 \\
\hline CTCCCGGCGC & TGTACGGCGA $\frac{\text { CCCCGCCCCA }}{\text { SP-1 }}$ & GCAGCCTGA $\underline{\underline{G}}$ & -59 \\
\hline$\frac{\text { GGGGCGGGAA }}{\text { SP-1 }}$ & ${ }_{-47}^{\text {CAGATGTCCG AGTGCGACAG }}$ & TATTGGTCGG & -19 \\
\hline CTTCCCCAGG & AAGCAGCC $\underset{+1}{*}$ ACGGAÄTAGG & $\underset{+20}{\text { CAAGCTTCCG }}$ & +22 \\
\hline GCGGGÄAGTG & AGCCẨGGGCT T TGGCGCGGCG & GCCGTGGTTG & +62 \\
\hline$\underset{+69}{\text { CGGCGCGGGÄ }}$ & AGTTT $\underset{+78}{\text { GGATC CTGGTTCCGT }}$ & CCGCTAGGAG & +102 \\
\hline
\end{tabular}

(B)
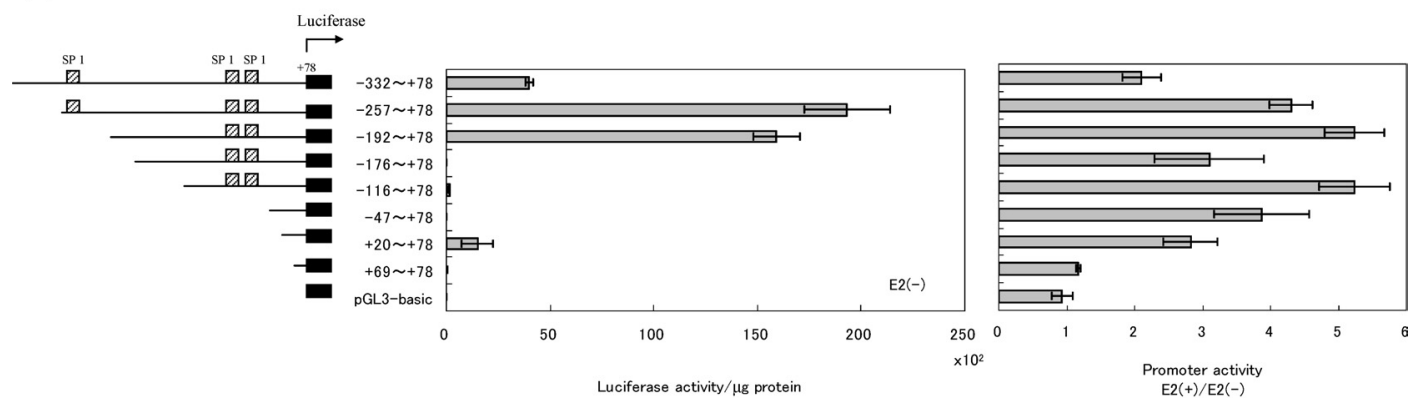

(C)
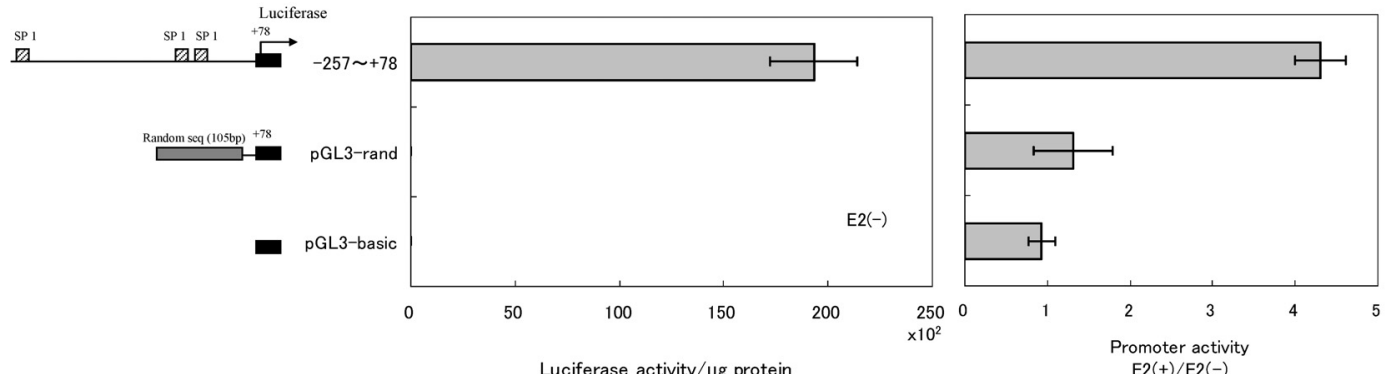

Fig. 5. (A) Sequence of the Proximal Upstream Region of $B L M$

The $B L M$ transcription start sites are indicated by asterisks. The cis-acting Sp1 element binding sites are underlined.

(B) Promoter Activities Detected in the Upstream Region of $B L M$

The structure of the plasmids are shown scheimatically on the left and the luciferase activities are shown in the central. Estrogen response of the $B L M$ upstream region are shown on the right. Reporter plasmids were transfected into MCF-7 cells with or without $10^{-9} \mathrm{M} \mathrm{E} 2$.

(C) Effects on Promoter Activity of a Random DNA Sequence by Replacing the BLM Upstream Region

Promoter activities detected in $-257-+78 B L M$ upregion and random DNA sequence are shown in the central. Estrogen response of $-257-+78$ BLM upregion and random DNA sequence are shown on the right. Each point represents mean \pm standard deviation of quadruplet samples. 
we determined the transcription start sites of $B L M$ by using a Cap site cloning method. The $5^{\prime}-B L M$ cap site of cDNA amplified by second PCR was cloned into pCR2.1. The DNA sequence that included the capping site of $B L M$ mRNA was determined to identify the transcription start sites of the $B L M$ gene. From DNA sequencing of 20 independent clones, $B L M$ was judged to be transcribed from multiple positions (Fig. $5 \mathrm{~A}$, asterisks); the position $(+72)$ was most frequent. We assume that most upstream start sites are at position $(+1)$ (Fig. 5A).

Deletion Analysis of the $\boldsymbol{B L} \boldsymbol{M}$ Promoter To define the region responsible for the $B L M$ promoter, serial deletion mutants were constructed as described in Materials and Methods. Three cis-acting Sp1 element binding sites clustered around the $300 \mathrm{bp}$ region (Fig. 5A). Although BLM mRNA expression increased by E2-treatment (Figs. 1A, B), suggesting that ER participates in its regulation (Figs. 1C, D), a consensus estrogen responsive element was not found in the upstream $2 \mathrm{kbp}$ region of $B L M$. Figure 5B shows the comparative promoter activity of a series of $5^{\prime}$-deletion mutants of pGL3-BLM and the E2 response to these mutants as assessed by luciferase activity in MCF-7 cells. The activities of pGL3 $\left(-257 \_+78\right)$ containing three Sp1 elements and pGL3(-192_+78) containing two Sp1 elements were distinct from other mutants. The activity of pGL3(-332+78 ) containing three Sp1 elements was less than for pGL3 $\left(-257 \_+78\right)$, indicating that region -332 to -257 induces a negative effect on the promoter activity. Once again, pGL3 $(-192 \ldots+78)$ showed marked promoter activity and pGL3 $(-176-+78)$ and pGL3 $(-116-+78)$ containing two Sp1 elements had little promoter activity, suggesting the region at -192 to -177 may be indispensable for $B L M$ transcription. Both pGL3 $(+20-+78)$ and pGL $(+69-$ $+78)$, which have no Sp1 element, showed minimal or slight
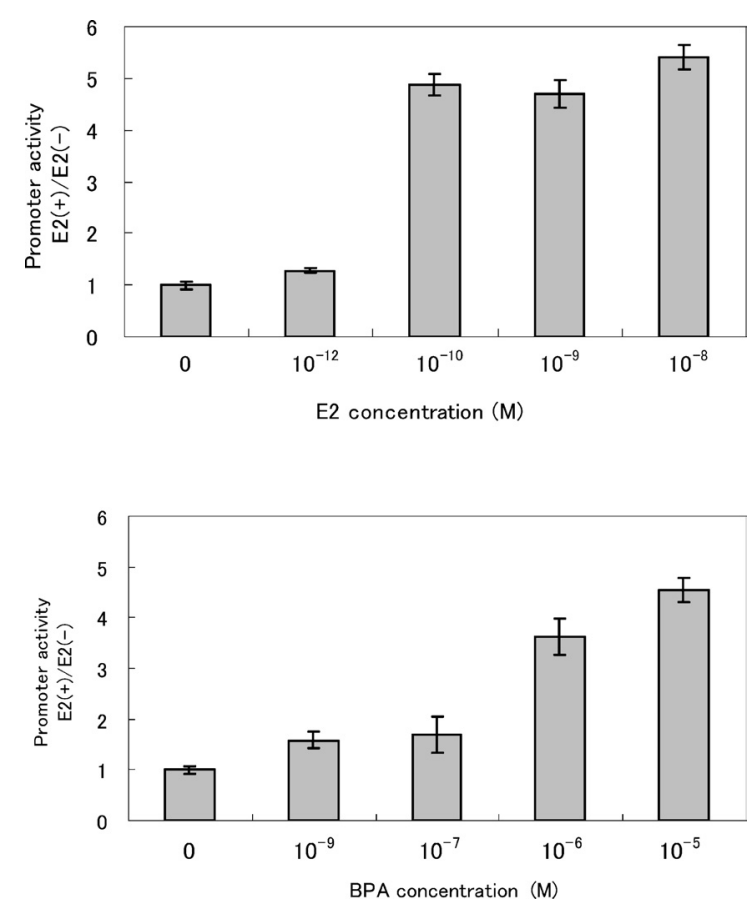

Fig. 6. Promoter Activities Induced by E2 and BPA

$-257-+78 B L M$ upregion-luciferase reporter plasimids were transiently transfected into MCF-7 cells; E2 or BPA are indicated doses. Each point represents mean \pm standard deviation of quadruplet samples. promoter activity. Figure $5 \mathrm{~B}$ in the right shows the ratio of activity of these $5^{\prime}$-deletion mutants of pGL3-BLM with and without E2. Apparent stimulation of the promoter activity by E2 was observed for pGL3(+20_+78) lacking SP1, suggesting that SP1 does not directly participate in E2 response.

When the $B L M$ upstream region at -258 to +18 was replaced with a random DNA sequence (103 bp), the $B L M$ transcription ability decreased to the level of the pGL3-basic vector (Fig. 5C), suggesting the $B L M$ upstream sequence $(-257$ to +18$)$ is essential for $B L M$ promoter activity.

Participation of ER in Stimulation of $B L M$ Promoter Activity Figure 6 shows that E2 and BPA stimulates $B L M$ promoter activity in dose dependently. BPA needed about 1000 times higher concentration to attain the same levels of E2 effect. Figure 7 shows that ICI182780 eliminated the effect of E2 as assessed by luciferase activity in MCF-7 cells. Basal levels of $B L M$ expression slightly decreased in the presence of ICI182780, but ICI182780 did not affect the number of viable cells (data not shown). These results of E2 and BPA of the effect on promoter activity by BLM support the idea that they up-regulate the expression of BLM protein by increasing the transcription of $B L M$.

\section{DISCUSSION}

We showed that E2 or BPA stimulated the expression of BLM protein by ER. BLM protein relates to DNA replication and recombination or DNA repair and is expressed during late $\mathrm{S}$ and $\mathrm{G} 2$ phase. $^{23)}$ The expression of BLM protein is up-regulated during a log-phase and decreases at a stationary
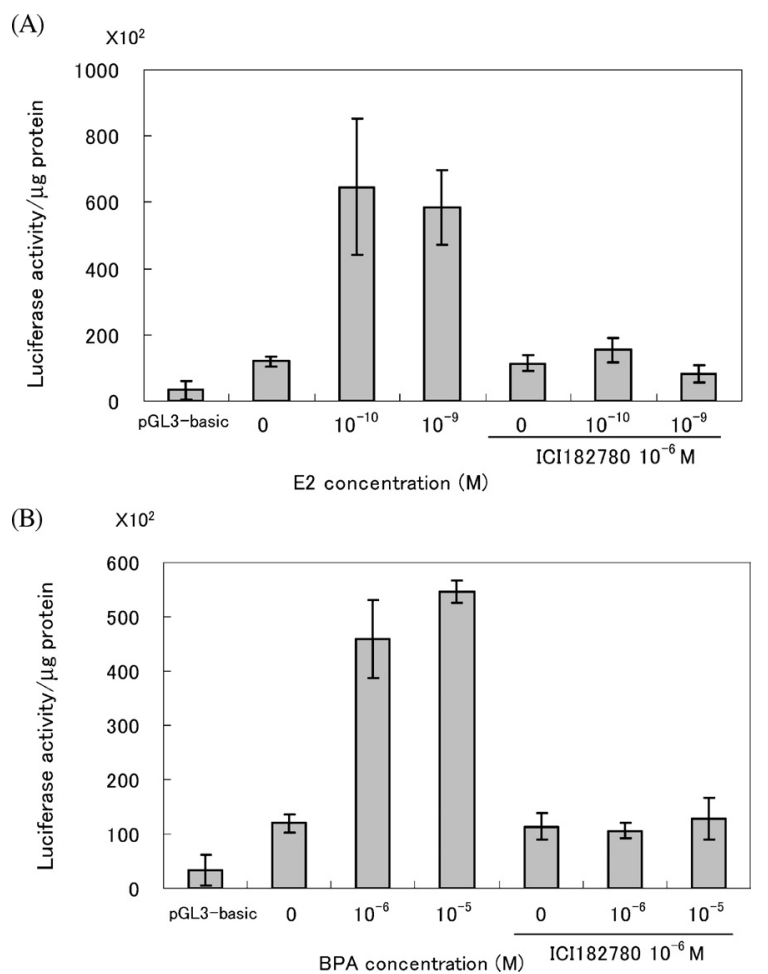

Fig. 7. ER Participation in Inducing Promoter Activity

$-257-+78 B L M$ upregion-luciferase reporter plasimids were transiently transfected into MCF-7 cells and were treated with $10^{-6} \mathrm{M}$ ICI182780 (ICI) for $1 \mathrm{~h}$ and then were stimulated with (A) $10^{-10}$ and $10^{-9} \mathrm{M}$ E2 or (B) $10^{-6}$ and $10^{-5} \mathrm{M}$ BPA. After $48 \mathrm{~h}$ the lucferasse activities were measured. Each point represents mean \pm standard deviation of quadruplet samples. pGL3-basic has no promoter region upstream of the firefly luciferase gene. 
phase for various tumor cells. ${ }^{16)}$ The expression of $B L M$ and cell cycle-associated genes was up-regulated by E2 and BPA that responding to increased cell proliferation. The up-regulation was observed at later stages after their treatment, that is, at $24 \mathrm{~h}$ (Figs. 1B, 2B), suggesting that the $B L M$ expression may be secondary after stimulation of cell proliferation by E2. On the other hand, the DNA damaging effect by E2 and BPA was observed much ealier than growth stimulation, ${ }^{10}$ suggesting that the DNA damaging effect is a direct effect by E2 and BPA.

The $2.3 \mathrm{~kb} B L M$ upstream region contains no consensus estrogen responsive element, supporting also the speculation that up-regulation of $B L M$ is not a primary but a secondary, response by $\mathrm{E} 2$. We believe this study is the first on $B L M$ transcription regulation by E2 or BPA. Our findings suggest that basal $B L M$ expression is sustained by a $\mathrm{Sp} 1$ transcriptional control system similar to other housekeeping genes, and that up-regulation of $B L M$ by E2 is not mediated by SP1.

Finally, we suggest a possible role of up-regulated BLM proteins by E2 or BPA. We previously showed that E2 and BPA cause DNA damage by ER in MCF-7 cells and that BLM protein forms foci at DNA damage sites. ${ }^{10)}$ Both E2 and BPA accelerated ER positive MCF-7 cells growth, and also they caused DNA damage. This study showed that E2 and BPA markedly up-regulates the expression of $B L M$ suggesting its participation in genomic stability during activated cell proliferation.

Acknowledgements We thank Dr. Masanobu Sugimoto, GeneCare Research Institute, for his excellent discussion and help in reviewing this manuscript. This study was supported by the Japan Science and Technology Agency, Japan.

\section{REFERENCES}

1) Liehr J. G., Endocr. Rev., 21, 40-54 (2000).

2) Cavalieri E., Frenkel K., Liehr J. G., Rogan E., Roy D., J. Natl. Cancer Inst. Monogr., 27, 75-93 (2000).

3) Bhat H. K., Calaf G., Hei T. K., Loya T., Vadgama J. V., Proc. Natl. Acad. Sci. U.S.A., 100, 3913-3918 (2003).
4) Cavalieri E. L., Stack D. E., Devanesan P. D., Todorovic R., Dwivedy I., Higginbotham S., Johansson S. L., Patil K. D., Gross M. L., Gooden J. K., Ramanathan R., Cerny R. L., Rogan E. G., Proc. Natl. Acad. Sci. U.S.A., 94, 10937-10942 (1997).

5) Cavalieri E. L., Li K.-M., Balu N., Saeed M., Devanesan P., Higginbotham S., Zhao J., Gross M. L., Rogan E. G., Carcinogenesis, 23, 1071-1077 (2002).

6) Yared E., McMillan T. J., Martin F. L., Mutagenesis, 17, 345-352 (2002).

7) Chen Y., Liu X., Pisha E., Constantinou A. I., Hua Y., Shen L., van Breemen R. B., Elguindi E. C., Blond S. Y., Zhang F., Bolton J. L., Chem. Res. Toxicol., 13, 342-350 (2000).

8) Nutter L. M., Ngo E. O., Abul-Haji Y. J., J. Biol. Chem., 266, 1638016386 (1991).

9) Mobley J. A., Brueggemeier R. W., Carcinogenesis, 25, 3-9 (2004).

10) Iso T., Watanabe T., Iwamoto T., Shimamoto A., Furuichi Y., Biol. Pharm. Bull., 29, 206-210 (2006).

11) Krishnan A. V., Stathis P., Permuth S. F., Tokes L., Feldman D., Endocrinology, 132, 2279-2286 (1993).

12) Roy D., Palangat M., Chen C.-W., Thomas R. D., Colerangle J., Atkinson A., Yan Z.-J., J. Toxicol. Environ. Health, 50, 1-29 (1997).

13) Hillard C. A., Armstrong M. J., Bradt C. I., Hill R. B., Greenwood S. K., Galloway S. M., Environ. Mol. Mutagen., 31, 316-326 (1998).

14) Frasor J., Danes J. M., Komm B., Chang K. C. N., Lyttle C. R., Katzenellenbogen B. S., Endocrinology, 144, 4562-4574 (2003).

15) Soulez M., Parker M. G., J. Mol. Endocrinol., 27, 259-274 (2001).

16) Kawabe T., Tsuyama N., Kitao S., Nishikawa K., Shimamoto A., Shiratoi M., Matsumoto T., Anno K., Sato T., Mitsui Y., Seki M., Enomoto T., Goto M., Ellis N. A., Ide T., Furuichi Y., Sugimoto M., Oncogene, 19, $4764-4772$ (2000).

17) Shiratori M., Suzuki T., Itoh C., Goto M., Furuichi Y., Matsumoto T., Oncogene, 21, 2447-2454 (2002).

18) Shimamoto A., Kitao S., Ichikawa k., Suzuki N., Yamabe Y., Imamura O., Tokutake Y., Satoh M., Matsumoto T., Kuromitsu J., Kataoka H., Sugawara K., Sugawara M., Sugimoto M., Goto M., Furuichi Y., Proc. Natl. Acad. Sci. U.S.A., 93, 10913-10917 (1996).

19) Zeisler H., Jirecek S., Hohlagschwandtner M., Knöfler M., Tempfer C., Livingston J. C., Wien Klin Wochenschr., 114, 458 - 461 (2002).

20) Steinmetz R., Brown N. G., Allen D. L., Bigsby R. M., Ben-Jonathan N., Endocrinology, 138, 1780-1786 (1997).

21) Gould J. C., Leonard L. S., Maness S. C., Wagner B. L., Conner K., Zacharewski T., Safe S., McDonnell D. P., Gaido K. W., Mol. Cell. Endocrinol., 142, 203-214 (1998).

22) Leffers H., Næsby M., Vendelbo B., Skakkebæk N. E., Jørgensen M., Hum. Reprod., 16, 1037-1045 (2001).

23) Bischof O., Kim S.-H., Irving J., Beresten S., Ellis N. A., Campisi J., J. Biol. Chem., 153, 367-380 (2001). 